\title{
Iron and its relation to glycoconjugates in human globus pallidus
}

\author{
Kopani $\mathrm{M}^{1}$, Kopaniova $\mathrm{A}^{2}$, Caplovicova $\mathrm{M}^{3}$, Maruscakova $\mathrm{L}^{4}$, Sisovsky $\mathrm{V}^{5}$, Jakubovsky $\mathrm{J}^{6}$ \\ Institute of Medical Physics, Biophysics, Informatics and Telemedicine, Faculty of Medicine, Comenius University, \\ Bratislava, Slovakia.martin.kopani@fmed.uniba.sk
}

\begin{abstract}
Iron and eosinophilic, argyrophilic spheroid structures of glycoconjugates are observed in the pallidonigral system of human and nonhuman primates. In the present study, we map the localization and distribution of ferritin and hemosiderin and their relation to neutral and acidic (sulphated and carboxylated) glycoconjugates in human globus pallidus. We investigated tissues of human globus pallidus without any motor abnormalities and psychiatric symptoms. Acidic (Alcian blue, $\mathrm{AB}$ pH 2.5) and neutral glycoconjugates (PAS reaction) showed spheroid deposits with the size of $5-15 \mu \mathrm{m}$. Staining reaction utilizing $A B(\mathrm{pH} 1.0)$ displays sulphated fibers and highly sulphated $(\mathrm{AB} \mathrm{pH} 0.5)$ glycoconjugates round deposits. AF/AB pH 2.5 for separating sulphated from carboxylated glycoconjugates revealed the presence of both sulphated and carboxylated glycoconjugates. Perls' and Turnbull's positive reaction showed the presence of $\mathrm{Fe}$ (III) and $\mathrm{Fe}$ (II) (hemosiderin) and Ag-NOR reaction showed ferric phosphate (ferritin) deposits. Scanning electron microscope with microanalysis revealed the iron in glycoconjugates globular deposits. We suppose the presence of glycoconjugates in the samples is the result of elimination and inactivation of iron as inductor of reactive oxygen species. They can be a useful neuroprotective agent in CNS degradation (Tab. 2, Fig. 7, Ref. 44). Text in PDF www.elis.sk.

Key words: iron, brain, glycoconjugates, neuroprotective effect.
\end{abstract}

Iron is the most important metal with a high concentration in some regions of the brain. The basal ganglia have the highestiron concentrations in the brain, particularly the globus pallidus and substantia nigra (1). Basal ganglia iron accumulation is associated with neuronal death in Alzheimer disease, Parkinson disease, epilepsy, Huntington disease, dementia with Lewy bodies or multiple sclerosis (2-4). Iron catalyzes reactions forming reactive oxygen species (ROS) (5). However, its activity depends mosthly on its ligand-based environment. Iron in human tissues can be found in the form of ferritin and/or hemosiderin (its breakdown product) $(8,9)$. Perls's blue stain is traditionally used for iron detection. Tham and Cousar (10) used Perls's blue staining and silver stain (Ag-NOR) for iron detection in ringed sideroblast. They found that Ag-NOR method is a more sensitive marker for the iron deposition because of it stains lower amount of iron in ferric phosphate complex (ferritin).

Spheroid structures were observed in the pallido-nigral system of humans and nonhumans primates (11-13). These structures are

${ }^{1}$ Institute of Medical Physics, Biophysics, Informatics and Telemedicine, Faculty of Medicine, Comenius University, Bratislava, Slovakia, ${ }^{2} 2$ nd Department of Neurology, Faculty of Medicine, Comenius University, Bratislava, Slovakia, ${ }^{3}$ Department of Geology of Mineral Deposits, Faculty of Natural Sciences, Comenius University, Bratislava, Slovakia, ${ }^{4}$ Institute of Immunology, Faculty of Medicine, Comenius University, Bratislava, Slovakia, ${ }^{5}$ Institute of Pathology, Faculty of Medicine, Comenius University, Bratislava, Slovakia, and 'Institute of Histology and Embryology, Faculty of Medicine, Comenius University, Bratislava, Slovakia

Address for correspondence: M. Kopani, RND, PhD, Institute of Medical Physics, Biophysics, Informatics and Telemedicine, Faculty of Medicine, Comenius University, Spitalska 24, SK-813 72 Bratislava, Slovakia. Phone: +421.2.59357530

Acknowledgement: This work was supported by the COST CM 1103 . generally eosinophilic, argyrophilic and iron pigmented. The diameter of these structures ranges from 5 to $50 \mu \mathrm{m}$. Willwohl et al (14) suggest according to the cellular origin two groups of spheroid: the first one are spheroids from degenerative axons and the second from microglia. As human beings age, increasing numbers of small round amorphous bodies is found. These round shape deposits were clearly detected by hematoxilin-eosin, alcian blue at low $\mathrm{pH}$, PAS and Hale's dialysed iron $(15,16)$.

These results indicate the glycoconjugates composition of some of the spheroid structures. From this point of view, for the first time is investigated the localization and distribution of iron (ferritin/hemosiderin) and their relation to neutral and acidic (sulphated and carboxylated) spheroid glycoconjugate structures in human globus pallidus.

\section{Material and methods}

\section{Samples}

Postmortem brain tissue sections from globus pallidus externus were routinely obtained at autopsy to prepare tissue sections for the pathology diagnosis in our departments.

Tissues were taken from 18 individuals without clinical findings of any motor abnormalities, iron metabolism, movements involving limbs, face, tongues (Tab. 1).

\section{Light microscopy}

The samples were fixed in $10 \%$ formaldehyde for 24 hours and embedded in paraffin blocks, cut by microtome to $5 \mu \mathrm{m}$ thin sections and mounted on gelatin-coated slides. Sections were stained for general morphological purposes by haematoxylin and eosine, Perls' and Turnbull method, Alcian blue (AB), Periodic 
Tab. 1. Summary of the clinical diagnosis of individuals, sex, age and postmortem interval before taking samples from the globus pallidus.

\begin{tabular}{rcccc}
\hline Case & $\begin{array}{c}\text { Age } \\
\text { at death }\end{array}$ & Sex & $\begin{array}{c}\text { Cause } \\
\text { of death }\end{array}$ & $\begin{array}{c}\text { Postmortem } \\
\text { interval in hours }\end{array}$ \\
\hline 1 & 47 & M & gastritis & 10 \\
2 & 67 & M & ovary tumor & 7 \\
3 & 49 & fat embolus & 6 \\
4 & 58 & F & heart failure & 5 \\
5 & 59 & M & heart failure & 9 \\
6 & 74 & F & thrombosis & 10 \\
7 & 78 & M & colonadenocarcinoma & 9 \\
8 & 72 & F & disseminated tumor & 14 \\
9 & 26 & M & hemorrhagic shock & 8 \\
10 & 53 & M & cirrhosis & 7 \\
11 & 69 & F & heart failure & 10 \\
12 & 83 & F & heart failure & 8 \\
13 & 19 & M & nephritis & 6 \\
14 & 72 & F & peritonitis & 9 \\
15 & 85 & F & heart failure & 7 \\
16 & 48 & F & cirrhosis & 10 \\
17 & 53 & F & gastritis & 6 \\
\hline
\end{tabular}

acid-Schiff's (PAS), Alcian blue/aldehyde fuchsin (AF) and AgNOR (Tab. 2). Tissue sections were then covered by cover glass and the samples were examined under the light microscope Eclipse E50i (Nikon, Japan).

Scanning electron microscopy (SEM) and energy-dispersive $X$ ray analysis $(E D X)$

We used $3 \%$ fixation solution of glutar(di)aldehyde buffered by phosphate for scanning electron microscopy. Samples at autopsy were dehydrated in graded acetone, subjected to critical point drying of $\mathrm{CO}_{2}$ (CPD 030, BAL-TEC, BG PRÜFZERT). Specimens were mounted on carbon stubs and coated with layer of carbon in ion sputtering apparatus (SCD 050, BALZERS, Lichtenstein). They were examined using JXA 840 A (JEOL, Japan) with the accelerating voltage of $15 \mathrm{kV}$. Simultaneous EDX analysis was performed with the aid of KEVEX 3205-1200 (Kevex, Valencia, Ca). The time period of spectrum collection was 2 hours with the energy range 0.160 to $8 \mathrm{keV}$.

\section{Results}

Perls' reaction revealed a population of blue round deposits and small blue deposits of irregular shape (Fig. 1). The size of $\mathrm{Fe}(\mathrm{III})$ round deposits in diameter ranged from $10 \mu \mathrm{m}$ to $20 \mu \mathrm{m}$ and small irregular deposits were around $5 \mu \mathrm{m}$. Turnbull reaction for $\mathrm{Fe}(\mathrm{II})$ detection revealed very fine granular blue deposits located sporadically around glial cells (not shown). Space distribution of $\mathrm{Fe}(\mathrm{III})$ and $\mathrm{Fe}(\mathrm{II})$ ions corresponds to eosinophilic round, lamellar structures.

At the site of $\mathrm{Fe}(\mathrm{III})$ accumulation, Ag-NOR black-brown round deposits of regular shape were observed (Fig. 2). The size of these deposits in diameter ranged from $5 \mu \mathrm{m}$ to $20 \mu \mathrm{m}$. Argyrophilic inclusions were not present in glial cells.

Hematoxylin and eosine (HE) stained glial cells were identified according to morphological criteria from the literature $(19,20)$. Size and morphology of glial cells agree with those of non-damaged astrocytes (large oval nuclei), oligodendrocytes (smaller round nuclei) and microglia (elongated nuclei). HE revealed round, lamellar structures (Fig. 3). The size of these structures was from $15 \mu \mathrm{m}$ to $40 \mu \mathrm{m}$.

Alcian blue staining at $\mathrm{pH} 2,5$ showed blue round structures with the darker centers at the site of Fe(III) and Ag-NOR spheroids. The size of these structures was from $5 \mu \mathrm{m}$ to $25 \mu \mathrm{m}$ (Fig. 4 left). PAS staining method revealed the same round neutral glycoconjugate deposits near Alcian blue ones. Their size was in diameter from $5 \mu \mathrm{m}$ to $25 \mu \mathrm{m}$ (Fig. 4 right). The incidence of PAS positive round deposits was smaller than Alcian blue positive round deposits.

The staining procedures utilizing $\mathrm{AB}$ at $\mathrm{pH} 1.0$ displayed positive sulphated fibers (Fig. 5) and a weak positive reaction on the fringe of spheroid structures. The reaction for detection of very sulphated glycoconjugates ( $\mathrm{AB} \mathrm{pH} 0.5)$ was negative.

For separating sulphated (purple) from carboxylated glycoconjugates (blue), AF/AB pH 2.5 staining was performed (Fig. 6). From these results, an existence of two biochemically-distinct spheroids can be drawn, non-sulphated carboxylated ones and non-carboxylated sulphated ones. Some structures were stained purple/blue.

In neurons, there are massive deposits of a yellow-brown granular pigment (lipofuscin). Processes and axons do not react in Perls' reaction. Moderate demonstration of both pseudoneuronophagia and neuronophagia was seen. In countless neurons, there werere basophilic deposits of Nissl substance. Fiberization of white mass with the swelling foci was observed. These findings may be attributed to the initial state of presenile dementia.

At the site of Alcian blue positive deposits scanning electron microscopy (SEM) revealed regular globular deposits of the size from $5 \mu \mathrm{m}$ to $10 \mu \mathrm{m}$ (Fig. 7 left). Energy-dispersive $\mathrm{X}$ ray microanalysis of these deposits showed the presence of $\mathrm{P}, \mathrm{S}, \mathrm{Ca}, \mathrm{Cl}$ and Fe (Fig. 7 right).

\section{Discussion}

Iron deposits were found in places with a high metabolic activity around glial cells and are physiologically accumulated de-

Tab. 2. Histochemical reactions for the detection of glycoconjugates and iron.

\begin{tabular}{|c|c|c|}
\hline Procedure & References & Interpretation of staining reactions \\
\hline PAS & $(17)$ & $\begin{array}{l}\text { Periodate-reactive carbohydrates and/ } \\
\text { or glycogen, purple color }\end{array}$ \\
\hline$\overline{\mathrm{AB} \mathrm{pH} 0.5}$ & $(18)$ & $\begin{array}{l}\text { Very sulphated acidic glycoconjugates } \\
\text { Blue color }\end{array}$ \\
\hline$\overline{\mathrm{AB}} \mathrm{pH} 1.0$ & (18) & $\begin{array}{l}\text { Sulphated acidic glycoconjugates, blue } \\
\text { color }\end{array}$ \\
\hline $\mathrm{AB} \mathrm{pH} 2.5$ & (18) & $\begin{array}{l}\text { Acidic glycoconjugates (sulphated and } \\
\text { carboxylated), blue color }\end{array}$ \\
\hline$\overline{\mathrm{AF}} / \mathrm{AB} \mathrm{pH} 2.5$ & (17) & $\begin{array}{l}\text { To distinquish sulphated (purple) and car- } \\
\text { boxylated glycoconjugates (blue color) }\end{array}$ \\
\hline Perls' method & $(17)$ & Fe(III) ions, blue color \\
\hline Turnbull reaction & $(17)$ & Fe(II) ions, blue color \\
\hline Ag-NOR & $(17)$ & Black-brown color \\
\hline
\end{tabular}




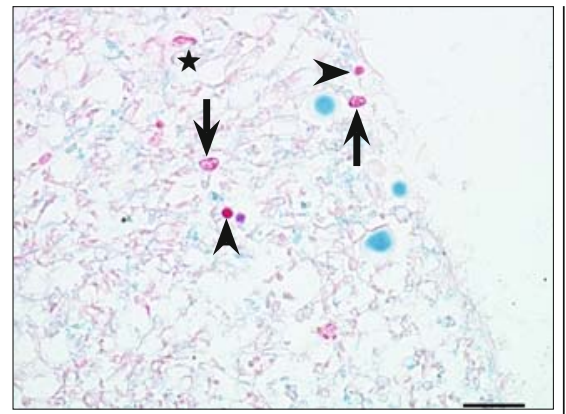

Fig. 1. Human brain, globuspallidus. Astrocytes are large oval nuclei (arrows), oligodendrocytes smaller round nuclei (arrowheads) and microglia elongated nuclei (asterisk). Blue dyed deposits correspond to the presence of $\mathrm{Fe}$ (III) ions. Scale bar $=30 \mu \mathrm{m}$.
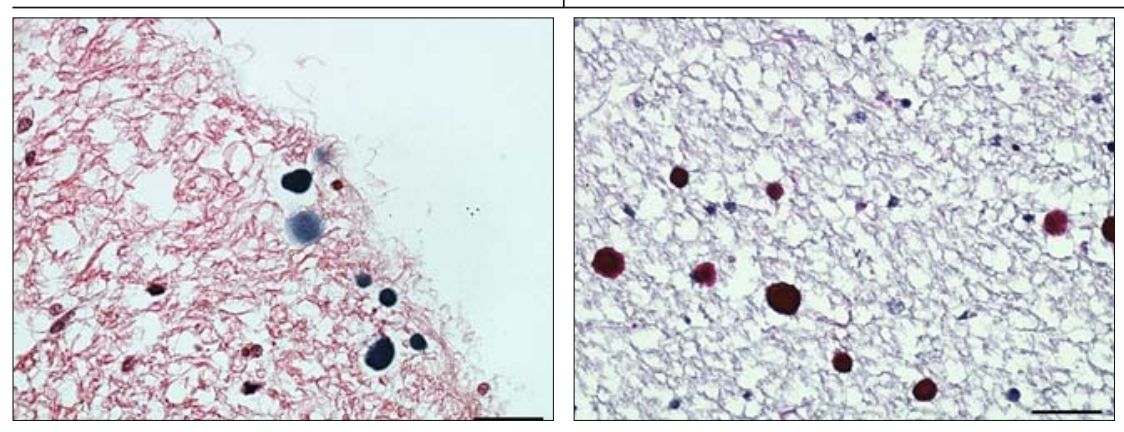

Fig. 4. Human brain, globuspallidus. Left-blue dyed deposits correspond to the presence of acidic glycoconjugates from the same areas as Figs 2 and 3. Alcian blue, pH 2.5, light microscopy. Right-purple dyed deposits correspond to the presence of neutral glycoconjugates. PAS reaction, light microscopy. Scale bar $=30 \mu \mathrm{m}$.

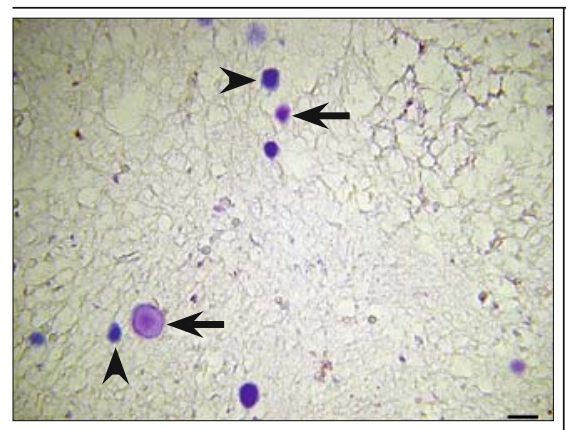

Fig. 6. Human brain, globuspallidus. Blue dyed round deposits (arrowheads) correspond to the presence of carboxylated glycoconjugates and purple dyed deposits (arrows) correspond to the presence of sulphated glycoconjugates in the vicinity of glial cells. Some structures were purple/blue dyed. AB/AF pH 2.5, light microscopy. Scale bar $=\mathbf{3 0} \mu \mathrm{m}$.

pending on age (21). Our findings of iron depositions near glial cells agree with the results of other studies (22-24). Oide et al (25) observed many grumose, foamy spheroid structures in globus pallidus containing ferric iron regardless of the presence of diseases or conditions $(26,27)$ and associated with iron mediated

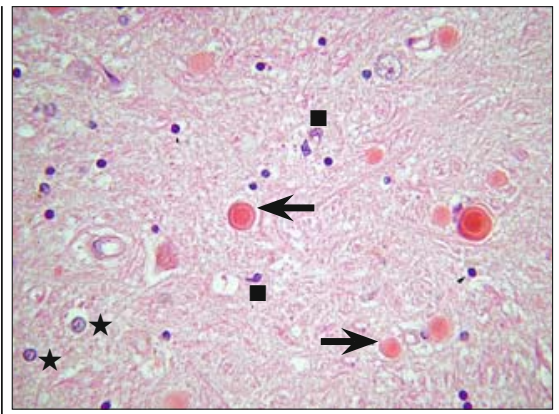

Fig. 3. Human brain, globuspallidus.Eosinophilic spheroid structures (arrows) in the vicinity of non-damage glial cells. Astrocytes are (asterisks), oligodendrocytes (arrowheads) and microglia elongated nuclei (squars). $\mathrm{HE}$, light microscope. Scale bar $=\mathbf{3 0} \mu \mathrm{m}$.

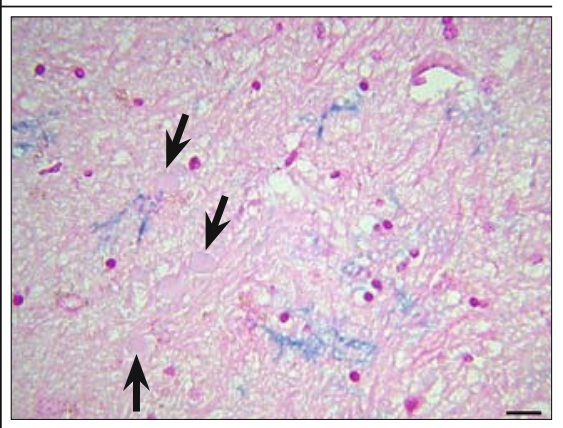

Fig. 5. Human brain, globuspallidus. Blue dyed fibers and a very weak positive reaction on the fringe of spheroid structures (arrows) correspond to the presence of sulphated glycoconjugates in the vicinity of glial cells. AB pH 1.0. Light microscopy. Scale bar $=\mathbf{3 0} \mu \mathrm{m}$.

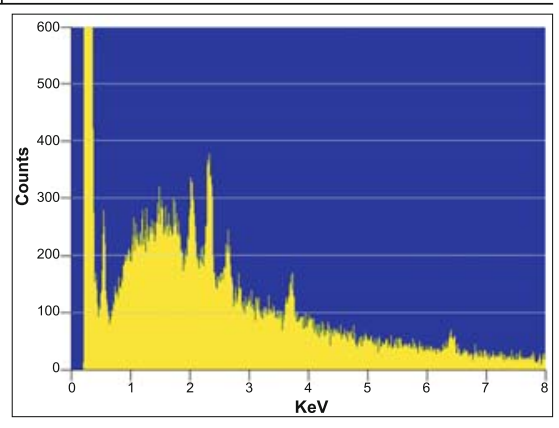

Fig. 7. Human brain, globuspallidus. Left-SEM of Alcian blue positive deposit. Right-EDX analysis of this deposit reveal the presence of iron. Accelerating voltage of $15 \mathrm{kV}$, scale bar $=5 \mu \mathrm{m}$.

oxidative stress. It was suggested that the presence of eosinophilic round structures evolve during aging are typical for globus pallidus degeneration. However, they were observed in globus pallidus without neurodegenerative diseases (11).

Bronson and Schoene (12) found spheroid-like structures and the iron pigment in monkey's globus pallidus. These structures were eosinophilic and argyrophilic and consisted of aggregations of dense globules and granules interspersed with membranes. They concluded that these structures might clarify pathogenesis of spheroid degenerations such as Hallervorden-Spatz disease. It 
is a rare disorder characterized by progressive extrapyramidal dysfunction and dementia with the accumulation of iron in the brain, mainly in the globus pallidus and substantia nigra.

Singhrao et al $(28,29)$ found positive reactions to antiferritin antibodies. These results showed oligodendroglial metabolites made an important contribution to their composition. Positive antibody reactions indicated that spheroid structures apparently consisted of materials derived from glial cells (30). This view is supported by multielemental composition of spheroid structures measured by $\mathrm{X}$ ray microanalysis $(31,32)$. They found $\mathrm{Ca}, \mathrm{Fe}, \mathrm{P}$, $\mathrm{S}$ what is in agreement with our results.

Sulphated and nonsulphated glycoconjugates on cell surfaces and as a part of extracellular matrix (perineuronal nets, $\mathrm{PN}$ ) can be found $(33,34)$. Glycoconjugates are complex macromolecules containing polysaccharides side chains covalently linked to a protein backbone. They interact with $\mathrm{Fe}$ (III) cations to form water soluble complexes $(35,36)$ or serve as a template assembly of nanocrystals $(37,38)$. Formation of globular deposits of glycoconjugates may reflect the higher exposition of glial cells to ferritin and hemosiderin. Processes of Fe cations binding to the negatively charged group of polysaccharides may be the mechanisms for mitigation of cell damages by ROS and may prevent injuries of CNS by reactive oxygen species $(39,40)$. In addition, increased cellular iron level enhances the secretion of matrix metalloproteinases (MMP-9) and through IL-1 $\beta$ maturation (41) the synthesis of heparansulphate proteoglycan (42).

Aquino et al (43) evaluated the occurrence and function of sulfated and carboxylated polysaccharides in plants. They found that carboxylated polysaccharides biosynthesis in environment with higher salinity was higher than sulphated ones. They concluded that negatively charged cell wall polysaccharides might play a role in coping with salt stress.

From the results of the present paper, we suggest that spheroid structures play a role in the absorption and accumulation of inorganic materials. Glycoconjugates bindind to iron may allow it to become coated efficiently with these molecules capable of preventing attack and a strong immune response. The present study revealed a significant heterogeneity of the glycoconjugates molecules (neutral, sulphated and carboxylated). This may reflect different stages of iron/ferritin accumulation. Glycoconjugates molecules are believed to have important function on cell surfaces and extracellular matrix as they regulate the uptake of iron ions and various digestion products and prevent degradation and damage of CNS.

\section{Conclusion}

We found hemosiderin and ferritin deposition in human brains without clinical-pathological findings. As a response to ferritin/ hemosiderin accumulation, glycoconjugates as components of extracellular matrix with neuroprotective effects by binding and scavenging redox-active iron ions and reduction of the oxidative stress in the cellular microenvironment were found. This mechanism can play a crucial role in neuroprotection of CNS against damages. The use of glycoconjugates as metal chelating agents can be useful in preventing degradation of CNS and may have a therapeutic effect by reducing the oxidative burst and the consequent cell damage.

\section{References}

1. Griffiths PD, Crossman AR. Distribution of iron in the basal ganglia and neocortex in postmortem tissue in Parkinson's disease and Alzheimer's disease. Dementia 1993; 4: 61-65.

2. Iozzo RV. Matrix proteoglycans: From molecular design to cellular function. Annu. Rev. Biochem 1998; 67: 609-652.

3. Friedland RP, Luxenberg JS, Koss E. A quantitative study of intracranial calcification in dementia of the Alzheimer type. Int Psychogeriatr 1990; 2: 36-43.

4. Jo DG, Lee JY, Hong YM, Song S, Mook-Jung I, Koh JY, Jung YK. Induction of pro-apoptotic calsenilin/DREAM/KChIP3 in Alzheimer's disease and cultured neurons after amyloid-beta exposure. J Neurochem 2004; 88: 604-611.

5. Vermersch P, Leys D, Pruvo JP, Clarisse J, Petit H. Parkinson's disease and basal ganglia calcifications: prevalence and clinico-radiological correlations. Clin Neurol Neurosurg 1992; 94: 213-217.

6. Ercal N, Gurer-Orhan H, Aykin-Burns N. Toxic metals and oxidative stress part I: Mechanisms involved in metal-induced oxidative damage. Curr Top Med Chem 2001; 1: 529-539.

7. Yantiri F, Andersen JK. The role of iron in Parkinson disease and 1-methyl-4-phenyl-1,2,3,6-tetrahydropyridine toxicity. IUBMB Life 1999; 48: 139-141.

8. Valko M, Rhodes CJ, Moncol J, Izakovic M, Mazur M. Free radicals, metals and antioxidants in oxidative stress-induced cancer. Chem Biol Interact 2006; 160: 1-40.

9. Bartzokis G, Aravagiri M, Oldendorf WH, Mintz J, Marder SR. Field dependent transverse relaxation rate increase may be a specific measure of tissue iron stores. Magn Reson Med 1993; 29: 459-464.

10. Bulte JW, Miller GF, Vymazal J, Brooks RA, Frank JA. Hepatic hemosiderosis in non-human primates: quantification of liver iron using different field strengths. Magn Reson Med 1997; 37: 530-536.

11. Tham KT, Cousar JB. Combined silver Perls's stain for differential staining of ringed sideroblasts and marrow iron. J Clin Pathol 1993; 46: 766-768.

12. Arai N, Mizutani T, Morimatsu Y. Foamy spheroid bodies in the globus pallidus and the substantia nigra pars reticulata: an investigation on regional distribution in 56 cases without neurodegenerative diseases. Virchows Arch A Pathol Anat 1993; 422: 307-311.

13. Bronson RT, Schoene WC. Spontaneous pallido-nigral accumulation of iron pigment and spheroid-like structures in macaque monkeys. J Neuropathol Exp Neurol 1980; 39: 181-196.

14. Siddiqi ZA, Peters A. The effect of aging on pars compacta of the substantia nigra in rhesus monkey. J Neuropathol Exp Neurol 1999; 58: 903-920.

15. Willwohl D, Kettner M, Braak H, Hubbard GB, Dick EJ Jr, Cox AB, Schultz C. Pallido-nigral spheroids in nonhuman primates: accumulation of heat shock proteins in astroglial processes. Acta Neuropathol 2002; 103: 276-280.

16. Nishimura A, Sawada S, Ushiyama I, Yamamoto Y, Nakagawa T, Tanegashima A, Nishi K. Lectin-histochemical detection of degenerative glycoconjugate deposits in human brain. Forens Sci Inter 2000, 113: 265-269. 
17. Anzil AP, Herrlinger H, Blinzinger K, Kronski D. Intraneuritic corpora amylacea, Virchows Arch A Pathol Anat Histol 1974; 364: 297-301.

18. Bancroft JD, Gamble M (Eds). Theory and practice of histological techniques. London: Churchill Livingstone, 2002.

19. Lev R, Spicer SS. Specific staining of sulphate groups with alcian blue at low pH. J Histochem Cytochem 1964; 12: 309-309.

20. Kattenmann H, Ransom BR (Eds.). Neuroglia. Oxford: Oxford University Press, 2005.

21. Pannese E. (Eds). Neurocytology. Fine structure of neurons, nerve processes, and neuroglia cells. New York: Thieme Medical Publisher, 1994.

22. Connor JR, Menzies SL, Burdo JR, Boyer PJ. Iron and iron management proteins in neurobiology. Pediatr Neurol 2001; 25: 118-129.

23. Casanova MF, Araque JM. Mineralization of the basal ganglia: implications for neuropsychiatry, pathology and neuroimaging. Psychiatry Res 2003; 121: 59-87.

24. Kobayashi S, Yamadoni I, Miki H, Ohmori M. Idiopathic non-arteriosclerotic cerebral calcification (Fahr's disease): an electron microscopic study. Acta Neuropathol 1987; 73: 62-66.

25. Morris CM, Candy JM, Oakley AE, Bloxham CA, Edwardson JA. Histochemical distribution of non-haem iron in the human brain. Acta Anat (Basel) 1992; 144: 235-257.

26. Oide T, Yoshida K, Kaneko K, Ohta M, Arima K. Iron overload and antioxidative role of perivascular astrocytes in aceruloplasminemia. Neuropathol Appl Neurobiol 2006; 32: 170-176.

27. Kaneko K, Yoshida K, Arima K, Ohara S, Miyajima H, Kato T, Ohta M, Ikeda S. Astrocytic deformity and globular structures are characteristic of the brains of patients with aceruloplasminemia. J Neuropathol Exp Neurol 2002; 61: 1069-1077.

28. Arai N. Grumose or foamy spheroid bodies involving astrocytes in the human brain. Neuropathol Appl Neurobiol 1995; 21: 238-245.

29. Singhrao SK, Neal JW, Piddlesden SJ, Newman GR. New immunocytochemical evidence for a neuronal/oligodendroglial origin for corpora amylacea. Neuropathol Appl Neurobiol 1994; 20: 66-73.

30. Singhrao SK, Morgan BP, Neal JW, Newman GR. Functional role for corpora amylacea based on evidence from complement studies. Neurodeg 1995; 4: 335-345.

31. Cavanagh JB. Corpora-amylacea and the family of polyglucosan diseases. Brain Res Rev 1999; 29: 265-295.
32. Singhrao SK, Neal JW, Newman GR. Corpora amylacea could be an indicator of neurodegeneration. Neuropathol Appl Neurobiol 1993; 19: $269-276$

33. Tokutake S, Nagase H, Morisaki S, Oyanagi S. X-ray microprobe analysis of corpora amylacea. Neuropathol Appl Neurobiol 1995; 21: 269-273.

34. Turley EA. Proteoglycans and cell adhesion. Their putative role during tumorigenesis. Cancer Metastasis Rev 1984; 3: 325-339.

35. Brückner G, Brauer K, Härtig W, Wolff JR, Rickmann MJ, Derouiche A, Delpech B, Girard N, Oertel WH, Reichenbach A. Perineuronal nets provide a polyanionic, glia-associated form of microenvironment around certain neurons in many parts of the rat brain. Glia 1993; 8: $183-200$.

36. Liu Q, Laskowski JS. The interactions between dextrin and metalhydroxides in aqueous-solutions. J Coll Interface Sci 1989; 130: 101-111.

37. Onsøyen E, Skaugrud O. Metal recovery using chitosan. J Chem Technol Biotechnol 1990; 49: 395-404.

38. Chan CS, De Stasio G, Welch SA, Girasole M, Frazer BH, Nesterova MV, Fakra S, Banfield JF. Microbial polysaccharides template assembly of nanocrystal fibers. Science 2004; 303: 1656-1658.

39. Archibald DD, Mann S. Template mineralization of self-assembled anisotropic lipid microstructures. Nature 1993; 364: 430-433.

40. Campo GM, Avenoso A, Campo S, Ferlazzo AM, Micali C, Zanghí L, Calatroni A. Hyaluronic acid and chondroitin-4-sulphate treatment reduces damage in carbon tetrachloride-induced acute rat liver injury. Life Sci 2004; 74: 1289-1305.

41. Wiedenheft B, Mosolf J, Willits D, Yeager M, Dryden KA, Young M, Douglas T. An archaeal antioxidant: Characterization of a Dps-like protein from Sulfolobus solfataricus. Proc Nat Acad Sci 2005; 102: 10551-10556.

42. Mairuae N, Connor JR, Cheepsunthorn P. Increased cellular iron levels affect matrix metalloproteinase expression and phagocytosis in activated microglia. Neurosci Lett 2011; 500: 36-40.

43. Schönbeck U, Mach F, Libby P. Generation of biologically active IL-1 beta by matrix metalloproteinases: a novel caspase-1-independent pathway of IL-1 beta processing. J Immunol 1998; 161: 3340-3346.

44. Aquino RS, Grativol C, Mourão PA. Rising from the sea: correlations between sulfated polysaccharides and salinity in plants. PLoS One 2011; 6: e18862. 